\section{Mental health consequences of violence}

\section{SUICIDALITY AND EXPOSURE TO SCHOOL-BASED VIOLENCE AMONG A NATIONALLY REPRESENTATIVE SAMPLE OF ASIAN AMERICAN AND PACIFIC ISLANDER YOUTH}

Sonali Rajan, Prerna Arora. Columbia University

\subsection{6/injuryprev-2020-savir. 14}

Statement of Purpose Asian Americans and Pacific Islanders (AAPI) are the fastest growing racial/ethnic minority group in the U.S. However, less focus has been paid to the rates of suicidal behaviors among AAPI youth, despite estimates placing suicide as the second leading cause of death among AAPI youth (15-24 years). At the same time, exposure to schoolbased violence has a long-term negative impact on youth outcomes. And recent research has noted that AAPI youth are more likely to be victimized in schools than their non-AAPI peers. The current study expands on the limited existing research and examines the relationship between suicidal behavior and exposure to school-based violence among a national sample of AAPI high school students.

Methods We conducted a secondary analysis of the CDC's most recent Youth Risk Behavior Surveillance System data $(\mathrm{n}=14,765)$.

Results Results demonstrated that the prevalence of AAPI youth engaging in suicidal behaviors does not differ significantly from other demographic subgroups. Further, a significant correlation between exposure to school-based violence (including having been threatened with a weapon and a perceived lack of safety at school) and four suicidal behaviors was observed among this sample of AAPI youth: considered suicide attempt: $\mathrm{r}=0.237, \mathrm{p}<0.001$; made a suicide plan: $\mathrm{r}=0.237, \mathrm{p}<0.001$; attempted suicide: $\mathrm{r}=0.164, \mathrm{p}<0.001$, had a suicide attempt that resulted in injury: $r=0.147$, $\mathrm{p}<0.001$.

Conclusions Our findings confirm that AAPI youth are engaging in suicidality behaviors and experiencing school-based violence at rates comparable to non-AAPI youth. We also demonstrate that a significant relationship between exposure to school violence and suicidality persists for this subgroup.

Significance Implications for integrating existing mental health practices with school-based violence prevention efforts and that are tailored specifically to the needs of AAPI youth are discussed.

\section{School violence}

\section{K-12 SCHOOL ENVIRONMENTAL RESPONSES TO GUN VIOLENCE: GAPS IN THE EVIDENCE}

Sonali Rajan, Louis Klarevas. Columbia University

10.1136/injuryprev-2020-savir.15

Statement of Purpose The US has experienced 48 active school shootings in the past twenty years. During this time, K-12 schools have undertaken efforts to modify their school environment in response to the anticipation of gun violence. However, it is unclear whether there is evidence that these strategies are effective.
Methods We identified the most common school tactics and policies that are being implemented in K-12 schools across the US: (1) target hardening (e.g. metal detectors, locked classroom doors, security cameras), (2) presence of zero tolerance policies, (3) presence of school resources officers (whether armed with lethal or non-lethal forces), (4) implementation of emergency preparedness programs (e.g. active shooter training drills and first-aid and hemorrhage control training programs), (5) behavioral threat assessment efforts, (6) policies that allow for teachers or administrators to be armed with firearms, and (7) notification technologies. We systematically reviewed the literature over the past two decades to determine i) which school environmental factors have evidence supporting their effectiveness at deterring gun violence and ii) where the gaps in the literature are.

Results Our work confirmed that while there is a large number of strategies available to schools, there is very limited empirical evidence as to their efficacy. Of the evidence that exists, a preliminary review of the literature indicates that behavioral threat assessment efforts may be effective and conversely, that certain hardening efforts such as metal detectors are not effective at deterring violence.

Conclusions Notably, K-12 schools are implementing several policies and practices intended to prevent gun violence that do not have an evidence-base.

Significance Our review also highlights the impact efforts may be having on child well-being and on school communities atlarge. Implications for future research and for how school professionals might more effectively consider available information about these safety strategies will be discussed.

\section{Violence prevention policy and advocacy}

\section{STATE EARNED INCOME TAX CREDIT POLICIES AND INTIMATE PARTNER HOMICIDE IN THE UNITED STATES, 1990-2016}

Caitlin Moe, Avanti Adhia, Amy T Edmonds, Stephen J Mooney, Heather D Hill, Frederick P Rivara, Ali Rowhani-Rahbar. University of Washington, Firearm Injury and Policy Research Program, Harborview Injury Prevention and Research Center

10.1136/injuryprev-2020-savir.16

The Earned Income Tax Credit (EITC) is the largest cash transfer program to low-income working families in the U.S. Some states augment the federal EITC with variable levels of generosity. As lack of finances is the most frequently-cited barrier for women to leave abusive relationships, federal and state EITCs could provide financial means to leave abusive relationships. However, the financial control associated with abuse and current EITC eligibility rules may hinder the program's use for this purpose. We hypothesized that increased generosity in state EITC's would be associated with a reduction in intimate partner homicide (IPH).

Approach Using multiply-imputed Supplementary Homicide Reports, we obtained state- and year-level counts of female IPH victims aged 18 or older for 1990-2016. Using a difference-in-differences approach and linear regression with stateand year- fixed effects, we assessed the impact of changes in EITC generosity on annual rates of IPH per 100,000 adult female population, adjusted for state economic productivity, welfare policies, demographic characteristics, firearm availability, and non-familial homicide rates. 